\title{
Resenha
}

\section{Os desafios da Teologia Latino-Americana diante do contemporâneo}

\section{THE CHALLENGES OF LATIN AMERICAN THEOLOGY AHEAD THE CONTEMPORARY}

\author{
Alonso S. Gonçalves*
}

RIBEIRO, Claudio de Oliveira. Testemunho e libertação: a teologia latino-americana em questão. São Paulo: Fonte Editorial, 2016, 162p.

Procurar refletir criticamente sobre algo tão importante na trajetória de vida, não é uma tarefa muito fácil. Claudio de Oliveira Ribeiro, tem uma caminhada ecumênica marcada por um tempo significativo de auxílio e pastoreio em Comunidades Eclesiais de Base (CEBs). Como pastor metodista, foi formado na geração de pastores e teólogos marcados por questões políticas e sociais muito evidentes, que convocava para uma militância não apenas intelectual, mas, principalmente, uma práxis que atendesse os anseios e a esperança de uma gente marcada pelo espólio, não apenas de bens, mas de subsistência. Nesse contexto, a teologia latino-americana da libertação encontrou mais uma voz em Claudio Ribeiro. Uma voz que ecoaria os desmandos e os principais problemas de um sistema que tem como marca a desintegração do ser humano, o emudecimento dos corpos, a subalternidade de uma gente. Olhar para esses cenários em décadas anteriores, principalmente a partir de 1960, causaria repulsa, indignação e espírito combativo em pessoas

* Doutorando e Mestre em Ciências da Religião (2014); Licenciatura em Filosofia (2006); Bacharel em Teologia (2004). Realiza estudos, com o apoio da CAPES (Coordenação de Aperfeiçoamento de Pessoal de Nível Superior), na Universidade Metodista de São Paulo, pesquisando Teologia das Religiões e Diálogo Inter-religioso a partir da Teologia Protestante. Contato: alonso3134@hotmail.com; Lattes: <http://lattes.cnpq. br/1066881650609101>. 
como Claudio Ribeiro que, a partir da vivência do evangelho, sentiu-se convocado a contribuir, com o propósito de alargar entendimentos e municiar pessoas para lutas ainda maiores. Por isso, o seu envolvimento em organismos que tinha/tem como principal escopo igrejas, organizações e comunidades, tendo como elemento principal a teologia latino-americana como campo de atuação.

Dito isso, se faz importante o texto que agora resenhamos. O texto em questão não saiu das mãos de um teólogo comprometido apenas com a academia, mas de um agente de pastoral preocupado com os desafios que a contemporaneidade apresenta para a teologia latino-americana e sua práxis. Alinhando essas duas perspectivas (academia e pastoral), Ribeiro nos entrega um texto bem escrito e pontual, uma vez que ainda é rara a tentativa de elencar críticas ad intra, principalmente de alguém que está comprometido com o próprio projeto que critica. Nesse caso, os apontamentos são necessários, porque eles têm como principal objetivo dar novos contornos para uma reflexão teológica ainda pujante e necessária, não por acaso que em outro texto, Ribeiro ${ }^{1}$ se pergunta: "A teologia da libertação morreu?". Como ela não morreu, o autor procura trazer as principais lacunas que a teologia latino-americana precisa atentar, para continuar a dialogar e entender o contemporâneo com seus desafios prementes.

Atento aos novos desafios da contemporaneidade, o autor trabalha com alguns pressupostos: a complexidade da realidade socioeconômica e religiosa, principalmente na América Latina; as formas de espiritualidade; o pluralismo religioso. Esses são os principais pressupostos para o diálogo com a teologia latino-americana que o autor procura fazer e, como consequência, tecer algumas críticas. Para tal tarefa, acolhe autores/as, igualmente comprometidos/as com a teologia latino-americana da libertação, a fim de trazer algo de consistente, que tenha prospectivas para futuras reflexões. Diante desse quadro, o texto foi dividido em quatro capítulos: (1) A difícil arte da revisão; (2) O legado do pensamento crítico: a revisão feita "por dentro"; (3) Vozes de uma teologia feminista latino-americana; (4) Teologia e sensibilidade. No primeiro capítulo, o autor quer demonstrar de que a realidade, até então

1 RIBEIRO, Claudio de Oliveira. A teologia da libertação morreu?: reino de Deus e espiritualidade hoje. São Paulo/Aparecida: Fonte Editorial/Santuário, 2010. 
concebida pela teologia latino-americana, sofreu profundas e complexas mudanças. Se antes as análises poderiam ser feitas a partir de bipolaridades como "dominantes versus dominados", na contemporaneidade isso não se mostra mais possível, porque há uma clara "percepção de que o mundo mudou” (p. 14). Além do teórico Edgar Morin, conhecido por empreender uma reflexão transdisciplinar e desenvolver um pensamento complexo, o autor traz para a discussão Franz Hinkelammert, Nestor Canclini e Homi Bhabha. Esses pensadores fornecem ao autor aportes teóricos para se pensar na complexidade da realidade e nas mudanças pela qual o mundo passa/ou. Lançadas suas bases teóricas, o autor passa a elencar a contribuição de teólogos que forneceram elementos de reflexão e revisão a partir da teologia latino-americana. $\mathrm{O}$ segundo capítulo está focado em autores como Hugo Assmann, Juan Luis Segundo, Júlio de Santa Ana e José Comblin. São teólogos que se dedicaram a pensar a teologia latino-americana com o intuito de rever seus principais conceitos e assim, demonstrar as dificuldades da "Teologia da Libertação em se confrontar devidamente com a conjuntura e estrutura social e as indicações teórico-práticas" (p. 84). No terceiro capítulo, Ribeiro destaca o papel de algumas mulheres na teologia latino-americana, destacando suas inquietações, além de demonstrar a rica contribuição dessas mulheres na caminhada teológica. Nessa seleção, que poderia ser ampliada facilmente, Ribeiro coloca Ivone Gebara, Elza Tamez, Maria Clara Bingemer e Marcela Althaus-Reid. Cada uma delas olhando para uma perspectiva, quer da corporeidade, da espiritualidade, de gênero e homossexualidade. Trazendo essas mulheres para o debate revisionista, Ribeiro espera uma superação de posturas androcêntricas e sexistas, geradas, principalmente, com imagens distorcidas de Deus. O autor coloca em pauta a contribuição dessas mulheres, a fim de forjar novas imagens de Deus. Um Deus comprometido com a solidariedade e a justiça para com todos, mas, em especial, para com as mulheres que, infelizmente, são vítimas de violência e da falta de direitos. No último capítulo, Ribeiro continua sua tarefa de revisionista da teologia latino-americana e intitula o último capítulo de Teologia e sensibilidade. Com esse capítulo, o autor acolhe as contribuições de Gustavo Gutiérrez, Leonardo Boff e Milton Schwantes. Em cada um dos autores selecionados, Ribeiro realça uma característica dentre 
tantas. Em Gutiérrez, aborda a questão do sofrimento, um tema que vai além das análises teórica-sociais, porque interessa "responder a um contexto marcado por profunda dor e sofrimento, para os quais o ser humano nem sempre encontrará muitas explicações racionais devido a sua fragilidade como pessoa humana" (p. 129). Com Boff, o tema da ecoteologia está em pauta, porque "há uma unidade sagrada firmada em uma coexistência dinâmica e interligada de matéria, energia e espírito; daí a refutação das concepções dicotômicas, especialmente entre corpo e alma, matéria e espírito, ciências naturais e ciências sociais" (p. 135). A novidade desse capítulo, é a abordagem que o autor faz da caminhada teológica de Milton Schwantes. Na obra, Ribeiro realça a militância social de Schwantes aliada à leitura popular da Bíblia. O trabalho pastoral de Schwantes é lembrado. Uma pastoral preocupada com o social e que teve a Bíblia como principal linguagem para falar das questões que afetam os mais pobres, dependentes de uma atenção maior de Deus. Nesse sentido, havia uma "correlação entre a Bíblia e a vida para que simplificações fossem evitadas" (p. 147). Essas simplificações que o autor se refere, se dá em evitar leituras descomprometidas com contextos sociais que são marcados por lutas e dilemas.

O texto que Ribeiro nos oferece está centrado em três pressupostos: "alargamento metodológico para uma compreensão mais apurada da complexidade social; articulação mais adequada entre as formas de racionalidade que marcam a reflexão teológica latino-americana; aprofundamento das questões que emergem da valorização do pluralismo religioso" (p. 125). A partir desses eixos de discussão, o autor traçou uma linha demarcatória de posturas e reflexões críticas. Nesse sentido, o texto supre uma carência, ou seja, não há um texto que recolhe os principais nomes da teologia latino-americana em seus aspectos críticos. Além disso, a presença das mulheres, geralmente ignoradas por razões conhecidas, é salutar na obra. A contribuição das mulheres para a reflexão teológica latino-americana é destacada pelo autor com mérito, principalmente quando há sinais inequívocos de que as mulheres foram preteridas em análises dicotômicas e bipolares na trajetória da teologia latino-americana.

Um destaque é a presença de teólogos de tradição protestante na obra como de católicos. Por isso, o texto se mostra de interesse 
ecumênico, correspondendo a trajetória ecumênica do autor. O leitor/a que conhece a teologia latino-americana, sentirá a ausência de Rubem Alves, teólogo que é conhecido como um dos precursores da teologia latino-americana da libertação. A crítica de Alves se dá a partir da linguagem, quando está é utilizada para elaborar discursos a partir do contexto político e social. Ele trabalha essa abordagem em um dos seus livros, $O$ suspiro dos oprimidos. ${ }^{2}$ Com Rubem Alves, o texto do autor ganharia a perspectiva do lúdico e da poesia, que, para alguns, acolher essas duas formas de linguagem, pode soar como desnecessária e ainda revelar preocupações de cunho burguês, mas no texto do autor ampliaria ainda mais o debate por ter em Alves um crítico do discurso e, ao mesmo tempo, um poeta que faz refletir a esperança tendo como meios para alimentá-la a vida, o cheiro e os jardins. Ele seria mais um autor a entrar no último capítulo, Teologia e sensibilidade.

A obra Testemunho e libertação, é um caminho aberto pelo autor com o desejo de que as análises elencadas sejam trabalhadas a fim de ganhar novas leituras e novos proponentes. Por essas e outras razões, a obra é recomendada para leitores/as que sejam ávidos por reflexões que atendem ao espírito do contemporâneo.

2 ALVES, Rubem. O suspiro dos oprimidos. São Paulo: Paulinas, 1984. 